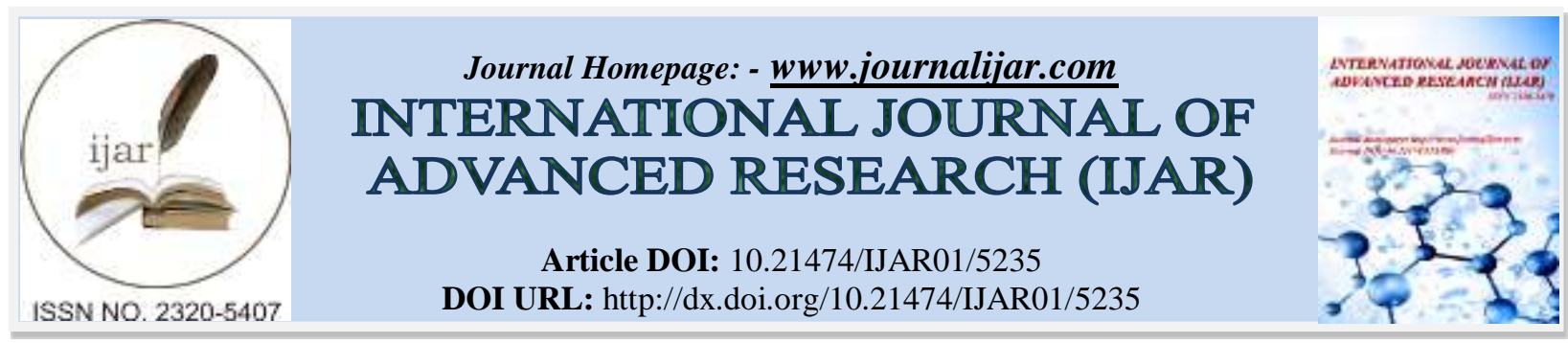

RESEARCH ARTICLE

\title{
SET FOR TRIPANOSOMOZ'S (SU-AURU) DIAGNOSTICS.
}

\section{Shabdarbayeva G. ${ }^{2}$, Akhmetsadykov N. ${ }^{1}$, Balgimbaeva A. ${ }^{2}$, Ibazhanova A. ${ }^{2}$, Khussainov.$^{2}$, Amirgaliyeva S., ${ }^{2}$, Turganbayeva G. ${ }^{2}$ and Kidirov T. ${ }^{2}$}

1. «Antigen» scientific and production enterprise, Kazakhstan, Almaty region.

2. Kazakh national agricultural university, Kazakhstan, Almaty.

\section{Manuscript Info}

Manuscript History

Received: 21 June 2017

Final Accepted: 23 July 2017

Published: August 2017

Key words:-

Trypanosomes, infecting agent, Trypanosoma evansi, field strain, passage, infestation blood, parazitemia, immunodepressants, trypanosomosis weight, trypanosomes antigene, specificity, sensitivity, hyper immunization, positive and negative serums, liophilization, serological tests, set of components.

\begin{abstract}
The technology of preparation of a set for diagnostics of a trypanosomosis (su auru) which consists of the following stages is given in article: allocation of a field strain of the Trypanosoma evansi activator; maintenance of a strain of Trypanosoma evansi on experimental animals: white mice, rabbits, guinea pigs, dogs, donkeys, horses; strengthening of virulence of a strain of Trypanosoma evansi repeated passages of the activator through an organism of susceptible animals, especially dogs and donkeys, and also by introduction infected animal immunodepressants; receiving from animals infestation blood trypanosomes their draining of blood a la carte is also total; obtaining tripanosomes weight by centrifugation of blood and washing of trypanosomes weight; desintegrating and resuspension of trypanosomes weight; office of a specific trypanosomosis anti-gene; standardization of an anti-gene on serological activity; stabilization of an antigene liophilization; receiving hyper immunized (positive) serums; receiving negative serums; test for specificity and sensitivity by statement various the serological of tests: complement binding reaction (CBR), complement long binding reaction (CLBR) and the enzyme-linked immunosorbent assay (ELISA); formation of components of a set; labeling and packing.
\end{abstract}

Copy Right, IJAR, 2017,. All rights reserved.

\section{Relevance:-}

Trypanosomes of camels and horses (synonyms: the su auru, the sura, to a sarys, a atpa, Murina, Mal-de-Kaderas, a derranga, Dera) - a parasitic transmissive disease, is characterized by defeat of plasma of blood, the alternating fever, a ca, death cachexia of animals.

Transmissive invasive diseases, in particular, trypanosomosis (su auru), are characterized by the exhausting alternating fever, anemia, jaundice, a hemoglobinuria, violation of digestive, cardiovascular, nervous, motive systems, decrease in all types of efficiency, a strong cachexia, up to a cachexia, big percent of a lethality. Spread of an illness fluctuates from 15 to $50 \%[1,2]$.

The sets of instruments for diagnosis based on use of low-sensitive tests, such as the reaction of a precipitation (RP), the agglutination reaction ( $\mathrm{AR}$ ), the reaction of a zhelephecation (RZ), the reaction of binding of a complement (RBC) and others don't allow to make authentically and in due time the diagnosis on trypanosomosis [3,4,5,6,7]. At 
the same time, the sets developed abroad on IFA-diagnostics are expensive, created without biological features of local strains of the activator by su auru. There for Kazakhstan is forced to use for diagnosis of the certified invasive disease - a trypanosomosis of test system, buying them abroad.

The sets developed abroad on IFA-diagnostics are expensive, created without biological features of local strains of causative agents of diseases. There for release of the domestic sets created on the basis of local strains of the activator is an actual and timely task, will allow to solve an import substitution problem, to adjust biologically safe diagnostic preparations of new generation, to create the enterprise for production of biological products. Operating time of anti-genes from parasites in large volumes for a variety of reasons quite labor-consuming, but feasible task. Feature of preparation of diagnosticume at parasitic diseases is that they are trained from parasites that out of an organism of a susceptible animal, for example in test tubes, on nutrient mediums, etc., can't exist. That in enough to prepare diagnosticumes, it is necessary to support constantly experimentally infected laboratory or expensive farm animals. And at deterioration in their state not to lose an activator strain, it is necessary to infect new party of animals that assumes big economic expenses. But on the other hand these expenses will be justified by the fact that the biotechnological industry of our country will receive the fulfilled technology of preparation of sets for diagnostics of su aura; the domestic sets of instruments for diagnosis capable to replace foreign preparations; reduction in cost of mass diagnostic testings; new productions and workplaces.

Trypanosomosis (the sura, su auru) is the certified disease during the importing and evacuation of animals that even more increases importance of a problem of diagnosis of this disease. The main problem consists in lack of a domestic diagnosticum. Feature of preparation of diagnosticum at the parasitoses is that they are prepared from parasites which out of an organism of a susceptible animal can't exist. That in enough to prepare diagnosticumes, it is necessary to support constantly experimentally infected expensive agricultural animals, and for collecting infestation blood it is necessary to exsanguinate them it is total that is for a variety of reasons quite labor-consuming $[8,9,10]$.

\section{Materials and methods:-}

Researches were conducted within the project financed by the Ministry of Education and Science of the Republic of Kazakhstan (MAUN RK) No. 0115PK00667 «Development and the organization of production of a set for diagnostics of a trypanosomosis (sou aura) of camels and horses with introduction of the GMP standard». Metrological providing devices and the equipment is carried out by the Kazakh center of standardization and metrology. Patent and license work is carried out according to GOST 150182. The assessment of statistical reliability of distinctions of researches is carried out by means of the computer Statistica program (version 6,0) with use of the test of $\mathrm{t}$-distribution of Styyudent for selections with normal distribution, or nonparametric criteria Uilkoksona-Mann-Whitney.

At allocation of a strain were clinically and suspicious horses in a disease and camels are microscopically investigated. Has been received from spontaneously infected animals with trilone-B blood, infestation trypanosomes. For the purpose of allocation of a field strain infestation blood has been entered intraparietal and intradermal by a related animal (5 donkeys) and laboratory animals ( 3 dogs, 5 rabbits, 10 white mice and 5 guinea pigs). For the infected animals conducted clinical and microscopic control of increase of a parazitemia. Blood was taken from peripheral vessels (from an ear or a tail) method of «a thick drop» and at once investigated under a microscope (increase h400) on existence of the live moving trypanosomes with their calculation, that is with determination of the intensity of an invasion (II). In the presence in one field of vision (the item 3.) microscope more than 100-120 trypanosomes collected blood from these animals and entered new party of laboratory animals. Thus, carried out accumulation of parasitic weight during the long period. At accumulation of parasitic weight also used clinical, parasitological (microscopic) methods, and also biological test and maintenance of a strain of Trypanosoma evansi on laboratory animals (white mice, guinea pigs, rabbits, dogs) and on closely related large animals (donkeys, mules, not purebred horses, colts). The strain is constantly supported by method of repeated passages on laboratory and farm animals by an injection infestation parasites of blood with trilone-B hypodermically and intraparietal. Adaptation of a field strain of Trypanosoma evansi and strengthening of its virulence it is carried out by application of various immunodepressants (a cyclophospomide, a hydrocortisone) for suppression of immunity at animals and provocation of a sharp course of disease for the purpose of obtaining the largest mass of trypanosomes. By microscopic methods investigated dynamics of emergence of trypanosomes in peripheral blood. At height of a parazitemia of laboratory animals exsanguinated it is total, and agricultural animals - a la carte (partially). The best producers of infestation blood are dogs and donkeys $[9,10]$. For accumulation of parasitic mass of trypanosomes, 
separations of trypanosomes from other components of bioptant were applied the ways [11] developed by us and protected by the Kazakhstan patents.

For receiving hyperimmune (positive) serum horses, donkeys who were immunized infestation blood have been used. Negative serum is received from obviously healthy animals of the current year of birth who didn't have contact with su auru carriers.

Preparation of the main component of a set - a tripanosome anti-gene from infestation blood differs from preparation of anti-genes from the endoglobular a little, that is intracellular blood parasite as trypanosomes are localized in blood serum. Preparation of an antigene also takes place several stages: filtering of infestation blood via the double gauze filter; centrifugation of blood for the purpose of her stratification and office of trypanosome weight; washing of trypanosome weight; the graduated disintegration of trypanosomes by means of UZDN-2 dispergator in 3 receptions; deposit resuspension; office of sediment liquid - a specific tripanosomny anti-gene; liophilization and packaging [12].

Approbation of a set has been carried out to several the serological tests: CFT, LCFR, ELISA

\section{Results:-}

The strain of Trypanosoma evansi is allocated by us from a sick camel in Tastemirov private enterprise of the village Arys of Arys district of the Southern Kazakhstan area in 2012 and is supported on white mice, rabbits, guinea pigs and dogs by parasitological methods in vitro by a repeated passage through animals under microscopic control of degree of an infestation (Figure 1).

The allocated strain of Trypanosoma evansi has been deposited with depositaries of «Research institute of problems of Biological safety», Flocks in 2014, registration number M-06-14/D is assigned to a strain and on him the certificate of deposition is received. For production of a tripanosome antigene at the enterprise there is a working strain of Trypanosoma evansi which is constantly supported on laboratory animals (dogs, rabbits, white mice) and on closely related animals (horses, donkeys, colts)) by infection and repeated passages (Figures 1 - 7).

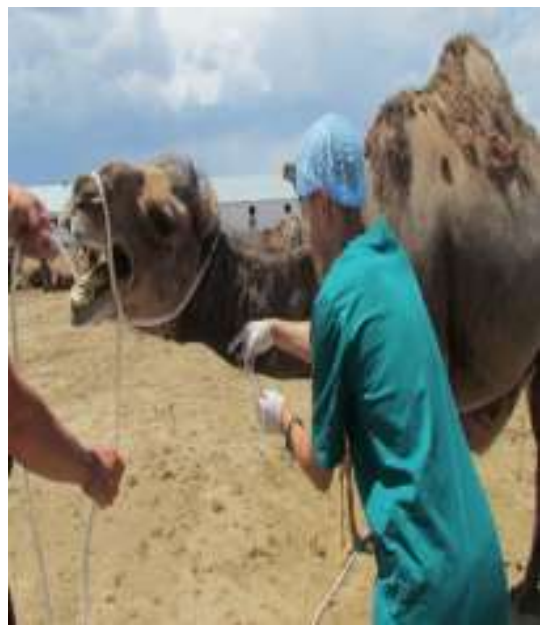

Figure 1 - Receiving a strain of Trypanosoma evansi from a sick camel

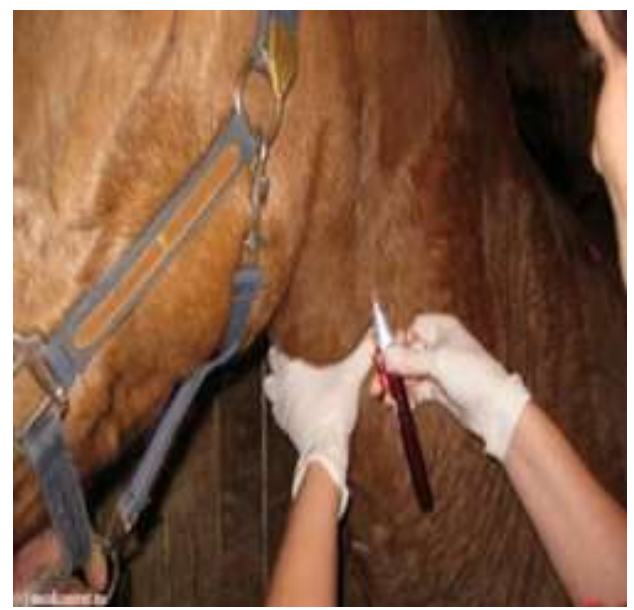

Figure $\mathbf{2}$ - Infection of a horse infestation trypanosomes blood 


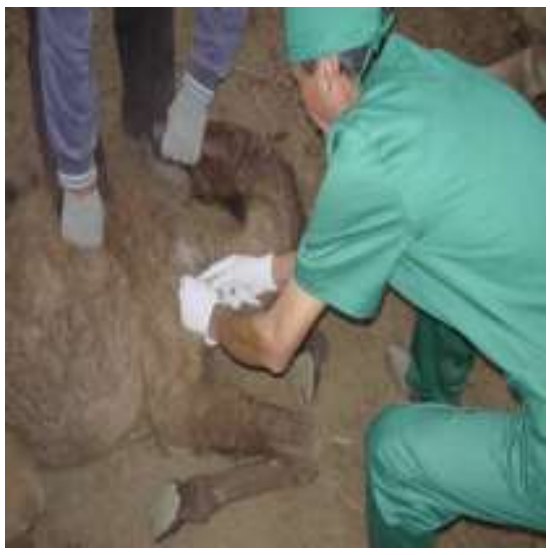

Figure 3 - Infection of a colt infestation trypanosomes blood

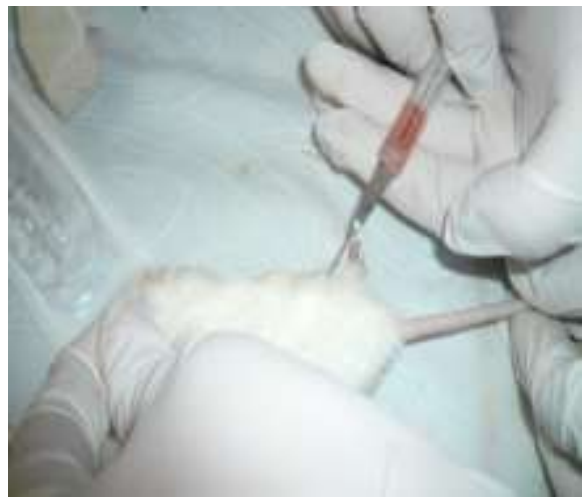

Figure 5 - Infection of white mice invasive trypanosomes blood

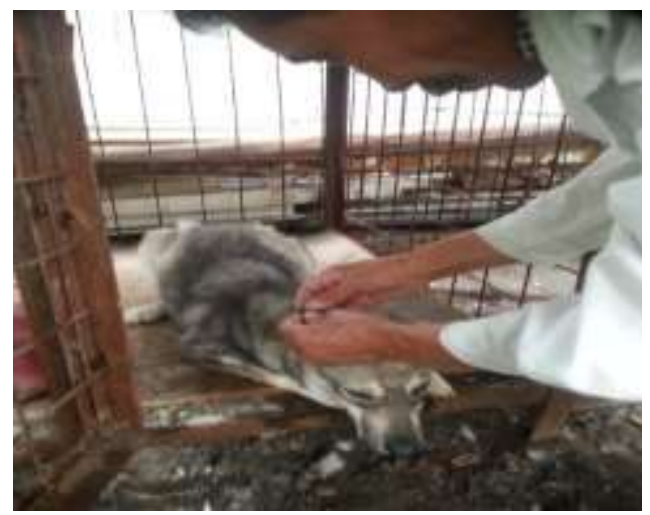

Figure 4 - Infection of a dog infestation trypanosomes blood

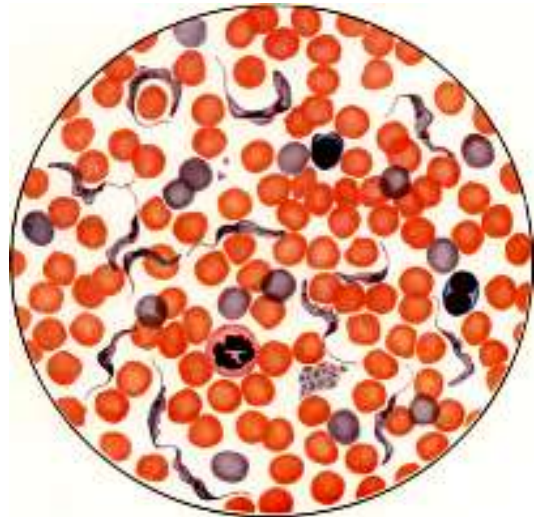

Figure 6 - Trypanosoma evansi trypanosomes in plasma of blood of animals

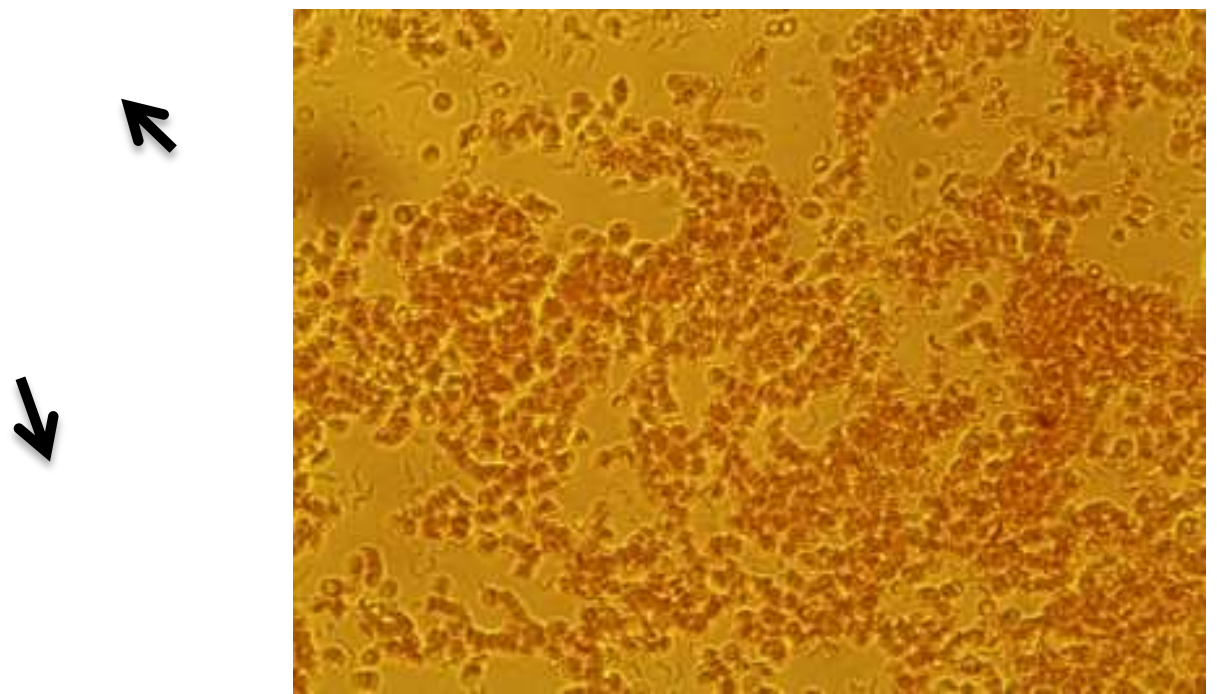

Figure 7 - A blood dab microphoto from the white mice infected with Trypanosoma evansi (increase x900)

After introduction by a laboratory animal of invazirovanny Trypanosoma evansi of blood about in 9-12 days at height of the parazitemiya reaching 20-50 parasites and more in 1 field of vision (the item 3.) a microscope from the infected mice took blood and entered her 2 nd party mice and, thus, have carried out a set of passages. Dynamics of a parazitemia was studied every 3 day up to death of the infected mice. On reproduction of trypanosomes in blood of 
laboratory animals the great influence is exerted by virulence of a strain and a method of infection. Virulence of the strain allocated with us was sufficient high, caused clinical display of an illness and death of the infected animal (mice) for 17-27 days and for 30-40 day (rabbits).

At the first passage of a trypanosome in blood of white mice appeared in single quantities (1-2 parasites in 1 item 3.) for 5-9 day, for 23-27 day the parazitemiya reached approximately to 75-100 trypanosomes in 1 item 3 . a microscope and then there occurred the death of all infected mice. At the second passage single parasites in blood appeared also for the 9th day, the parazitemiya reached a maximum (20-50:1 items 3.) for 26-27 days, the death of mice was noted for 26-27 days after infection. The third passage has yielded positive result for 6-9 days, then observed increase in a parazitemiya approximately twice every 3 day and for 18-21 days noted death of mice at a parazitemiya of the equal 90-100:1 item 3. The fourth, fifth and sixth passages have considerably truncated the term of appearance of parasites in blood, for the 3rd day the parazitemiya was from 5 to 40 trypanosomes in 1 item 3 . The death of mice was noted for 12-13 days.

The seventh and eighth passages have given a considerable parazitemiya (till 40-50 and 70-80 trypanosomes in 1 item 3.) for the 3rd day after infection and death of mice for 5-6 days at a parazitemiya from 70-80 to 90-100 parasites in 1 item 3. The ninth and tenth passages have given a considerable parazitemiya to 90-110 parasites in 1 item 3. literally for the 3rd day after infection and for 4-6 days it was noted by 100\% - Nye death of the infected mice. Strengthenings of virulence of trypanosomes and increase in parasitic weight tried to obtain reducing immunity of animals by means of introduction of immunodepressants, such as cyclophosphamide and a hydrocortisone or carrying out several passages through animals, susceptible to a trypanosomosis (dogs, donkeys, horses, camels). Researches conducted under constant microscopic control of a parazitemiya and at height of a parazitemiya took blood. Receiving infestation blood trypanosomes for production of an anti-gene was made in two options: from large animals (rabbits, dogs, donkeys) - blood was taken portsialno and it is total, and from small (white mice, rats) - it is total.

Infestation trypanosomes blood was exposed to processing in several stages. Stratification, office and washing of trypanosome weight carried out by centrifugation of blood within 20 minutes at $3000 \mathrm{rpm}$. Infestation blood at the same time was stratified on 3 layers: top - plasma and citrate; average - trypanosome weight; lower - uniform elements of blood. Office of the center - trypanosome weight carried out by means of the syringe and it is triple washed in physiological solution at $5000 \mathrm{rpm}$. for 10 minutes. The graduated disintegration of trypanosomes was carried out by the help of a dispergator of UZDN-2, carried out a deposit resuspension, led up $\mathrm{pH}$ to 8,0 - 8,2. Then processing by ultrasound with a frequency of $22-35 \mathrm{KHZ}, 40-60 \mathrm{~W} / \mathrm{sm}^{2}$ within 10 minutes and centrifugation of weight was carried out. Office of sediment liquid (lysate No. 3) that is a specific trypanosome antigene, carried out by means of the syringe. Each washed party of trypanosomes which is filled in with $0,5 \%$ solution of phenol in bottles represents a suspension of trypanosomes.

For receiving a series of an anti-gene took several suspensions, merged in a strong, thick-walled bottle and subjected on a reciprocating shaker within 48-52 hours. From parasitic weight prepared suspension on physiological solution with concentration of 10 billion parasitic cages in $1 \mathrm{ml}$. according to the optical standard of a turbidity also led up $\mathrm{pH}$ to 7,0-7,2 $0,1 \mathrm{~N}$ solution of caustic sodium. The received suspension of cultures was subjected to influence of ultrasound in the following modes: $\mathrm{KHz}$ frequency-22, power is-100 watts $/ \mathrm{sm}^{2}$. Influence time - 15 min. The destroyed parasitic weight was centrifuged within 30 minutes at 12-14 thousand rpm. Upon termination of centrifugation sediment liquid was exposed to isoionic fractionation for the purpose of allocation the antigen active of fractions (Figures 8, 9). 


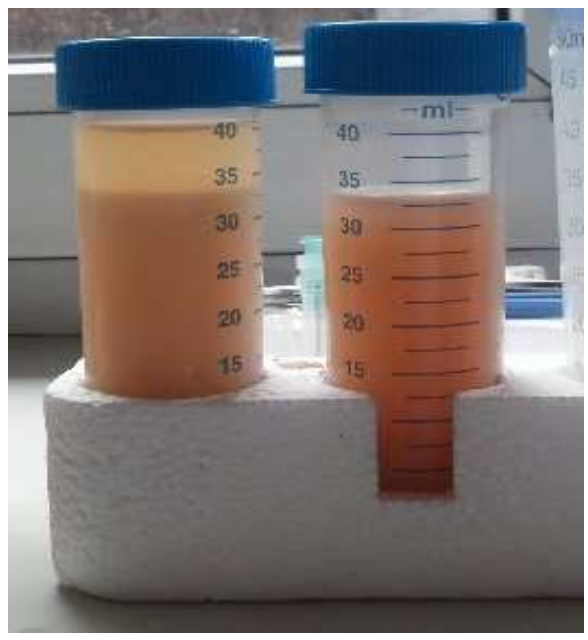

Figure 8 - Parasitic or tripanosome weight

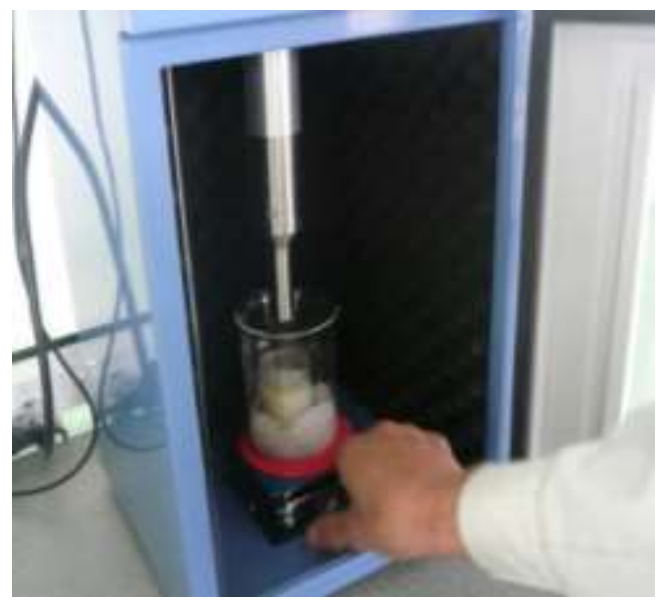

Figure 9 - Ultrasonic processing of a tripanosome antigene

Stabilization of a tripanosome anti-gene was carried out by a liophilization in a working caption with the protective environment, packed up and packed.

Standardization of an anti-gene on serological activity was carried out by a titration with hyperimmune tripanosome serums.

The following additional components are necessary for formation of the full set of instruments for diagnosis and carrying out at mass researches of control of specificity and sensitivity of the developed trypanosome antigene: positive serum (obviously positive serum), negative serum (obviously negative serum) thinner.

Positive serum (obviously positive serum) was received in two ways: from horses and, for reduction in cost of receiving anti-serums, from the rabbits who have undergone hyper immunization.

In the first case quality of producers selected the healthy, having average fatness horses, aged from the 3 rd till 5 years and it is powerful not lower than $250 \mathrm{~kg}$.

Animals were previously maintained on quarantine and investigated on infectious diseases according to the existing «Basic veterinary rules at preparation of animals in the biological industry». The horses which have appeared healthy were translated from quarantine for operation.

On everyone the arriving animal got an individual card in which fixed a state of health, age, results of research on infectious diseases, preventive inoculations and a method of operation.

Keeping of animals producers of antiserums has the features. In use producers subjected to researches on infectious diseases and to clinical examination. Results of research fixed in the corresponding books and individual cards. Behind producers conducted daily supervision, paying special attention to their physiological state, and also contents, strictly observing at the same time an individual approach to producers both at an antigene injection, and at blood capture. Rooms and care of animals have to meet veterinary health requirements. Producers it is necessary to let out daily for physical exercise on backyard platforms. Feeding of animals was made according to the approved norms.

Hyper immunization of horse producers, for the purpose of receiving positive serum, was carried out by subcutaneous injections of a tripanosome antigene every 5 days according to the following scheme (Table 1):

Table 1:- The scheme of immunization of horses producers for receiving positive serum

\begin{tabular}{|l|l|l|}
\hline Date & Type of manipulation & $\begin{array}{l}\text { The volume of a tripanosomny antigene } \\
\text { in } \mathrm{sm}^{3}\end{array}$ \\
\hline
\end{tabular}




\begin{tabular}{|l|l|l|}
\hline 1-st day & Introduction of an antigene & 3 \\
\hline 5- st day & Blood capture & - \\
\hline $10-$ st day & Blood capture & 7 \\
\hline 15- st day & Introduction of an antigene & - \\
\hline 20- st day & Blood capture & 7 \\
\hline 25- st day & Introduction of an antigene & - \\
\hline 30- st day & Blood capture & 7 \\
\hline 35- st day & Introduction of an antigene & - \\
\hline 40- st day & Blood capture & 7 \\
\hline 45- st day & Introduction of an antigene & \\
\hline and so on & & \\
\hline
\end{tabular}

In use to each producer every 5 days entered a trypanosome anti-gene and from each producer regularly for the 5th day after an injection of an antigene took samples of blood for definition of a caption of serum. In the first days of immunization for prevention of anaphylactic shock and for a sensitization, an organism the dose of a tripanosome antigene were minimum and made $3 \mathrm{sm}^{3}$, then at the following injection the dose of an anti-gene has been increased to $5 \mathrm{sm}^{3}$. Further in the absence of collateral reactions at horses, the dose of an antigene has been increased to $7 \mathrm{sm}^{3}$, as was a working dose at immunization. For the 5th day after each injection of a tripanosome anti-gene took from horse blood for establishment of a caption. In the presence of the serum caption established by the instruction the next introduction of an anti-gene wasn't made and these animals operated a long time. Animals whose serum doesn't possess the expressed complement fixation action were discarded.

Receiving positive serum was carried out as follows. Before everyone withdrawal of blood at animals took body temperature and made their weighing. Blood was taken only on condition of the normal body temperature of producers at the rate of $16 \mathrm{sm}^{3}$, by blood on $1 \mathrm{~kg}$ of live weight. In 12-14 hours prior to a withdrawal of blood of animals put on a hungry diet with an unlimited watering place.

Blood was taken from a jugular vein in the field of the top third of a neck, observing at the same time all measures of asepsis and antiseptics. Previously sterilized needle was entered one prick into a vein. Blood from each animal was collected in a separate sterile large bottle. After a withdrawal of blood the large bottle with blood was put in the thermostat for 1-2 hours at a temperature of $37^{\circ} \mathrm{C}$, then at the room temperature for 3-4 hours (for office of serum), then placed in inclined situation in the refrigerator at a temperature of $2-8^{\circ} \mathrm{C}$. After mixing serum was maintained by 8-10 days in the refrigerator, and then checked for sterility. Serum has to be sterile and shouldn't possess anticomplementary properties.

On the 3rd day made the 1st discharge of serum for 4-5-second. Serum from each horse was separately preserved admissible preservative and put for 10 days at a temperature of $2-8^{\circ} \mathrm{C}$, for a sediment. Then took sample of serum from each large bottle and subjected to check on sterility by seedings on MRS, MP, MLP under vaseline oil and Saburo's circle and on activity in CFT. In 10 days on condition of sterility and receiving positive results in CFT serum was decanted and mixed for drawing up a series.

The second option of receiving positive serums for a set at immunization of rabbits less labor-consuming and considerably cheap, has patent security.

The way of receiving anti-pyroplasma serum [13] is known. The antigen - the Fey et al method is known also a method of immunization of laboratory animals, 1976 [14], the antigen consisting in immunization of rabbits producers in mixes with the equal volume of the complete Freund's adjuvant (CFA), at the same time an anti-gene is entered into small pillows of paws of rabbits, on $0,25 \mathrm{sm}^{3}$ in everyone, protein content has to be not less than 5 $\mathrm{mg} / \mathrm{sm}^{3}$. In 21 days carry out an intramuscular injection to 2 points of mix of an anti-gene with CFA in the same dose. Blood sampling is begun from the 3rd day after the last injection. This way doesn't provide sufficient accumulation of antibodies, at the same time the caption of antibodies remains short time.

The way of receiving diagnostic serum (A.M. Safronov's method et al., 1976) consisting in immunization of rabbits producers in the 1st day by intravenous administration of an anti-gene is known: at first $0,002 \mathrm{mg}$ of protein, in 30 minutes of- $0,02 \mathrm{mg}$, and in 30 minutes - $2 \mathrm{mg}$. In 7 days - also 3 intravenous injections in doses of 0,002 mg; 0,02 
$\mathrm{mg}$, and $20 \mathrm{mg}$. Blood sampling is begun from the 3rd day after the last injection. [15]. He also doesn't provide sufficient accumulation of antibodies.

The way of receiving diagnostic serum (G. Frimel's method, 1987) [16], consisting in a combination of intramuscular and intravenous injections of an anti-gene is known: the 1st day - intramuscularly on $20 \mathrm{mg}$ of protein in 2 points of gluteuses; the 2nd day - intravenously $5 \mathrm{mg}$ of protein; the 3rd day - intravenously $5 \mathrm{mg}$ of protein. Blood sampling is begun from the 3rd day after the last injection. In this case the caption of antibodies remains short time.

We have developed more effective way of receiving positive serum which is solved the fact that carry out the combined introduction of an anti-gene to small pillows of pads, intramuscularly and intravenously [17,18]. The technical result provided with the invention is expressed in increase of specific activity of the received serums, prolongation of development of antibodies, prolongation of exploitation of animals producers, decrease in prime cost of a product.

The objectives have been achieved by the fact that animals were immunized according to the following scheme improved by us: the 1st day - a tripanosome anti-gene in mix with the equal volume of the complete Freund's adjuvant (CFA) in small pillows of paws of rabbits, on $0,25 \mathrm{sm}^{3}$ in everyone, protein content has to be not less than $5 \mathrm{mg} / \mathrm{sm}^{3}$, the 7 th day - intramuscularly on $20 \mathrm{mg}$ of protein in 2 points of gluteuses; the 14th day - intravenous immunization of rabbits according to the scheme: at first $0,02 \mathrm{mg}$ of protein, in 30 minutes $-0,2 \mathrm{mg}$, and in 30 minutes - $20 \mathrm{mg}$. In 21 days this manipulation was repeated. Blood sampling was begun from the 3rd day after the last injection of the 1st block of immunizations, carried out 40-50 ml of blood, it is triple, with an interval of 72 hours. Repeatedly blood was taken since 3rd day after intravenous immunization, according to the same scheme.

Further after short rest the cycle of immunization and a blood withdrawal repeated several times. Since 3rd day after the beginning of immunization, controlled a caption the precipitation of antibodies in the reaction of a quantitative precipitation (QPR) by the M.Heidelberger [19] method.

Owing to the fact that the offered way assumes repeated use of animals producers, with use of a phenomenon of a revaccination specific activity of the received serums considerably increases that increases efficiency and productivity of diagnostic tests.

The received serums are approved on sensitivity and specificity in the reaction of a quantitative precipitation (QPR), in comparison with serums in the received ways known earlier. Results of tests are presented in table 2.

Apparently from table 2, the offered way in comparison with known allows to receive diagnostic serums with higher specific activity and allows to use animal producers longer time that reduces prime cost of serums.

Table 2:- Results of tests of activity and specificity of positive serums

\begin{tabular}{|l|c|c|}
\hline \multicolumn{1}{|c|}{ Way of immunization } & $\begin{array}{l}\text { The average number of } \\
\text { days of exploitation of rabbits } \\
\text { producers }\end{array}$ & $\begin{array}{l}\text { Results the serological of reactions in } \\
\text { QPR (an average caption of serums), } \\
\text { mkg/ml }\end{array}$ \\
\hline Offered by us & 93 & 340 \\
\hline Method Fey et al. & 31 & 260 \\
\hline Method A.M. Safronova & 35 & 140 \\
\hline \multicolumn{1}{|c|}{ Method G. Frimel's } & 32 & 280 \\
\hline
\end{tabular}

Thus, the way of receiving the immune serum applied at serological diagnostics of a trypanosomosis provides (in comparison with the known ways) receiving highly active and high-specific serums with smaller expenses and a big exit of a preparation that allows to increase reliability the serological of reactions.

Serum from rabbit producers were collected in a large bottle, preserved admissible preservative for 10 days at a temperature of $2-8^{\circ} \mathrm{C}$, for a sediment. Then took sample of serum from each large bottle and subjected to check on sterility by seedings on MRS, MP, MLP under vaseline oil and Saburo's circle and on activity in CFT. In 10 days on condition of sterility and receiving positive results in CFT serum was decanted and mixed for drawing up a series, packaged $2 \mathrm{sm}^{3}$ in ampoules or bottles, ampoules soldered, and bottles corked traffic jams with aluminum caps and labeled. 
It is necessary to understand the quantity of a preparation mixed in one capacity, subjected to further processing in one working conditions, packaged in ampoules or bottles, which has got the number, number of state control and issued by one quality certificate as a series of positive serum.

The following component of a set - negative serum. For receiving negative serum before everyone withdrawal of blood at animals took body temperature and made their weighings. Blood was taken only on condition of the normal body temperature of producers at the rate of $16 \mathrm{sm}^{3}$, by blood on $1 \mathrm{~kg}$ of live weight. In 12-14 hours prior to a withdrawal of blood of animals put on a hungry diet with an unlimited watering place. Blood was taken from a jugular vein in the field of the top third of a neck, observing at the same time all measures of asepsis and antiseptics. Previously sterilized needle was entered one prick into a vein. Blood from each animal was collected in a separate sterile large bottle.

After a withdrawal of blood the large bottle with blood is put in the thermostat for 1-2 hours at a temperature of $37^{\circ} \mathrm{C}$ (at the room temperature for 3-4 hours) for office of serum, then placed in inclined situation in the refrigerator at a temperature of $2-8^{\circ} \mathrm{C}$.

On the 3rd day made the 1st discharge of serum, on the 4-5-second. Serum from each horse was separately stabilized admissible preservative and put for 10 days at a temperature of $2-8^{\circ} \mathrm{C}$, for sediment. Then took sample of serum from each large bottle and subjected to check on sterility by seedings on MPA, MPB, MPPB under vaseline oil and Saburo's circle. In 10 days on condition of sterility serum was decanted and mixed for drawing up a series. It is necessary to understand the quantity of a preparation mixed in one capacity, subjected to further processing in one working conditions, packaged in ampoules or bottles, which has got the number, number of state control and issued by one quality certificate as a series of negative serum.

After mixing serum was maintained by 8-10 days in the refrigerator, and then checked for sterility. Serum has to be sterile and shouldn't possess anticomplementary properties.

After check serum was packaged in ampoules or bottles on $2 \mathrm{sm}^{3}$, ampoules soldered, and bottles corked traffic jams with aluminum caps and label.

As thinner for all components of a set served physiological solution:-

By production of the set of instruments for diagnosis control of components of a set is obligatory. For this purpose carried out sampling in accordance with GOST 18321. For quality check of a set of different places of each series the controller does selection in number of $n=0,4 \sqrt{ } N$ (where to $n$-quantity of bottles, necessary for control, $N$ - the number of packings, places, etc. in a series). From selection select 6 packing units necessary for carrying out the analysis of indicators of quality according to the present standard of the organization. Three packing units use for test, and others three store in archive of department of biological control within 24 months. The samples of a set intended for storage in archive seal up and supply with the document of the established form. The samples of a set intended for test supply with a label on which in addition specify: date of selection of test; series volume; a position and the signature of the person which has selected test.

Determination of appearance, color, availability of foreign impurity, flakes, a mold, carry out violations of integrity visually in the passing light. Correctness of labeling is at the same time checked. Determination of sterility is carried out in accordance with GOST by 28085. Definition of vacuum in an anti-gene is carried out in accordance with GOST 28083 - there has to be a violet-blue luminescence. Definition of a mass fraction of moisture of an anti-gene is defined in accordance with GOST by 24061. The maintenance of a mass fraction of moisture in an anti-gene has to be $3 \div 1$ of $\%$. Determination of solubility of an anti-gene is checked addition of phosphatic and buffer or physiological solution in the quantity corresponding to anti-gene volume before drying. Contents of an ampoule have to be dissolved within 3-5 min. and represent transparent, slightly opalescent liquid of yellow color, without deposit and flakes. Bacterial frequency of an anti-gene for serological diagnostics of sou aura, serums negative, positive determines by microscopy of dabs from 1 bottle of each set painted on Gram or Kozlowski. In dabs there shouldn't be a foreign microflora.

Determination of activity and specificity of an anti-gene is carried out as follows. Take three ampoules of each component and add phosphatic and buffer solution or physiological solutions, in the ratio, specified on an anti-gene label. Contents of ampoules are united and from the received mix take $1 \mathrm{sm}^{3}$ of a component in experience. Activity 
of an anti-gene is checked by definition of a caption the complement-fixing of antibodies in CFT with specific serum, for a trypanosome anti-gene do cultivations 1:10, 1:20, 1:40. 1:80, 1:160, 1:320 also investigate with normal and specific serums of blood which take in the working cultivation specified on a label of a specific preparation. Cultivations of all components of reaction do on physiological solution. In parallel as control put reaction with specific and normal serums from a control on an anti-complementarity, haemotoxicity and with control of a dose of a complement.

In reaction use 2 working doses of a complement which define in preliminary titration. One hemolytic unit consider the maximum cultivation of a complement giving full гемолиз 2,5\% of erythrocytes of a ram at statement of reaction in hemolytic system. The haemolysine is used in a quadruple caption in mix with the equal capacity of $2,5 \%$ of erythrocytes of a ram. All components of reaction take of $0,1 \mathrm{sm}^{3}$. The total amount of mix in reaction makes 0,5 $\mathrm{sm}^{3}$. The phase of binding of a complement is carried out within 16-18 hour. On cold at a temperature $(4 \pm 0,5)^{\circ} \mathrm{C}$, a phase of a hemolysis - in the thermostat at $(37 \pm 1)^{\circ} \mathrm{C}$ within $30 \mathrm{~min}$. Reaction is considered within an hour after the termination of an incubation in the thermostat.

Results of reaction begin to consider with control. At the same time in a test tube where standard normal serum with a specific anti-gene and without antigene contains, has to come full hemolysis erythrocytes. Full гемолиз has to come also in the test tubes containing control specific serum with a normal anti-gene and without it (control of an anti-complementarity). The delay of a hemolysis has to be in the test tubes containing a specific anti-gene and specific serum and also in a test tube control on haemotoxicity.

Complement-fixing caption of a specific trypanosome anti-gene consider his maximum cultivation giving with working cultivation of specific serum a delay of a hemolysis not less than $50 \%$ of erythrocytes (3-4 crosses). The caption the $\mathrm{V}$ of antibodies of studied trypanosome anti-gene has to be not less than 1:40. Working cultivation of an anti-gene consider his quadruple limit caption.

Activity (caption), anticomplementary and hemolytic properties of positive and negative serum define in RSK For preparation of initial cultivations 1:5 studied series of serum and negative serum bring $0,5 \mathrm{sm}^{3}$ of each serum in test tubes, add 2,0 $\mathrm{sm}^{3}$ of physiological solution and mix a pipetting. A support with test tubes place in a water bath at a temperature $(60-62)^{\circ} \mathrm{C}$ for $30 \mathrm{~min}$. After warming up from initial cultivations of an studied series of serum positive on physiological solution $\mathrm{pH}$ 6,8 -7,2 prepare cultivations 1:10, 1:20, 1:40, 1:80. Necessary cultivations of serums are prepared in separate ranks of test tubes as follows: in a support install test tubes with initial cultivations of serums and supplement each row with 4 test tubes. Bring $1 \mathrm{sm}^{3}$ of physiological solution in test tubes of each row. From the first test tube $1 \mathrm{sm}^{3}$ cultivations bring in the second, mix, further in the third and so up to the end, and delete from the last $1 \mathrm{sm}^{3}$ of mix.

In other support establish two rows on 7 test tubes in everyone for statement of the main experience.

Statement of the main experience. Cultivations of serums, an anti-gene and a complement bring in the specified sequence $0,2 \mathrm{sm}^{3}$ in test tubes. At the same time put control of reaction according to the scheme provided in table 3 .

Table 3:- Driving performances and recording with a set of CFT for the serological diagnosis of trypanosomiasis

\begin{tabular}{|c|c|c|c|c|c|c|c|c|}
\hline \multirow[t]{2}{*}{ Name of serum } & \multirow{2}{*}{ Antigen } & \multicolumn{5}{|c|}{ Serum cultivations } & \multirow{2}{*}{$\begin{array}{l}\text { With out } \\
\text { serum }\end{array}$} & \multirow{2}{*}{$\begin{array}{l}\text { Wit hout serum } \\
\text { and a complement }\end{array}$} \\
\hline & & $1: 5$ & $1: 10$ & $1: 20$ & $1: 40$ & $1: 80$ & & \\
\hline \multirow{3}{*}{$\begin{array}{l}\text { Examinee } \\
\text { serum }\end{array}$} & Antigen & ++++ & ++++ & ++++ & ++++ & ++ & - & ++++ \\
\hline & $\begin{array}{l}\text { Without anti- } \\
\text { gene }\end{array}$ & - & - & - & - & - & - & ++++ \\
\hline & $\begin{array}{l}\text { Without anti- } \\
\text { gene and a } \\
\text { complement }\end{array}$ & ++++ & ++++ & ++++ & ++++ & ++++ & ++++ & ++++ \\
\hline \multirow[t]{3}{*}{ Negative serum } & Antigen & - & - & - & - & - & - & ++++ \\
\hline & $\begin{array}{l}\text { Without anti- } \\
\text { gene }\end{array}$ & - & - & - & - & - & - & ++++ \\
\hline & $\begin{array}{l}\text { Without anti- } \\
\text { gene and a } \\
\text { complement }\end{array}$ & +++ & +++ & +++ & +++ & +++ & +++ & ++++ \\
\hline
\end{tabular}


Instead of missing components bring $0,2 \mathrm{sm}^{3}$ of physiological solution in control test tubes. Supports with test tubes stir up and place in a water bath at a temperature $37-38^{\circ} \mathrm{C}$ for $20 \mathrm{~min}$. Then bring hemolytic system on $0,4 \mathrm{sm}^{3}$ in test tubes and again place in a water bath for $20 \mathrm{~min}$.

After a bath supports with test tubes maintain (15-18) h at a temperature of $15^{\circ} \mathrm{C}$ and make the accounting of reaction.

Reaction is considered in crosses on the 4th to ball system on degree of the delay of a hemolysis of erythrocytes expressed as a percentage:

++++ - $100 \%$ of a delay of a hemolysis of erythrocytes;

$+++-75 \%$ of a delay of a hemolysis of erythrocytes;

$++-50 \%$ of a delay of a hemolysis of erythrocytes;

$+-25 \%$ of a delay of a hemolysis of erythrocytes;

- - $0 \%$ of a delay of a hemolysis of erythrocytes.

Caption of positive serum in CFT consider her greatest cultivation silt causing full delay of a hemolysis of erythrocytes (lack of a hemolysis) with a trypanosome anti-gene in working cultivation.

Processing of results is carried out as follows. Serum positive is considered active if her caption in CFT about an anti-genome for serological diagnostics of sou aura of horses and camels is not below 1:20; not possessing anticomplementary and haemo-toxic properties if in control without anti-gene erythrocytes hemolysis completely ( $0 \%$ of a delay of a hemolysis), and test tubes without anti-gene and a complement there is a full delay of a hemolysis ( $100 \%$ of a delay of a hemolysis).

Serum negative in all cultivations shouldn't cause delays of a hemolysis of erythrocytes with an anti-gene trypanosomes for CFT, LCFR, shouldn't possess anti-complementary and haemo-toxic properties.

Reproducibility is defined on the control panel of manufacturer within one or several tablets by the analysis not less than in 10 repetitions (holes) of one test.

Sensitivity of a set is defined as the relation of amount of true and positive values which are taken for the analysis, to amount of in a false manner negative values which are expressed as a percentage.

Calculations carry out on the Formula:

$$
F=\frac{N i^{+}}{N i^{+}+N x^{-}} \cdot 100 \%
$$

where, $\mathrm{Ni}+$ amount of true and positive values, $\mathrm{Nx}-$ amount of false and negative values.

Marking, packing and storage of a set. The applied types of a container have to conform to requirements of Technical regulations «Requirements to safety of the medicines and biological preparations used in veterinary science», TR of the HARDWARE 005/2011, standards, other normative documents and contracts contracts for import production adopted (signed) in accordance with the established procedure.

The retail and transport container, and also the materials used for her production and corking means of domestic and import production have to be allowed for contact with production by bodies of veterinary supervision of the Republic of Kazakhstan.

The Trypanosome anti-gene for serological diagnostics of su auru is packaged in primary packing - sterile glass ampoules from neutral glass on $1 \mathrm{sm}^{3}$ or bottles on $1,0 \mathrm{sm}^{3}$, with a tolerance of $\pm 3 \%$ and subject liophilization, ampoules solder under vacuum, bottles close under vacuum. Ampoules solder, and bottles densely close the sterile rubber traffic jams which are pressed out by metal caps. 
Serums and negative package positive on $1,0 \mathrm{sm}^{3}$ in sterile bottles from neutral glass, cork sterile rubber traffic jams and roll aluminum caps. Other packing of reagents of a set coordinated in accordance with the established procedure is allowed. Bottles (ampoules) with reagents pack into cardboard boxes in accordance with GOST 12301 with existence of the nests and partitions ensuring safety of reagents of a set when transporting.

Boxes with sets pack into wooden boxes in accordance with GOST 5959, boxes from corrugated fibreboard in accordance with GOST 9142 or GOST 13481 ensuring safety of sets at transportation and storage Mass gross of boxes has to be no more than $15 \mathrm{~kg}$.

Put in each unit of a container in the state and Russian Manual languages on application of a set and a control leaf with the instruction: names of the manufacturing organization; names of a set; the number of boxes in a box; numbers of a series; numbers of control; dates of packing; expiration date; numbers and surnames of the packer. Boxes of corrugated fibre board have to be stuck together: a tape with a sticky layer in accordance with GOST 18251 brands B or B; a polyethylene tape with a sticky layer or a glue tape according to the document according to which it is made.

The marking conforming to requirements of Technical regulations «Requirements to safety of the medicines and biological preparations used in veterinary science», «Requirements to packing, marking, labeling and their correct drawing», executed directly on packing or on a label has to be applied on each unit of packing. On each bottle (ampoule) of a set the label or indelible paint on glass has to be pasted. In each box put manual on application.

Transport marking is made in accordance with GOST 14192 with the indication of handling instructions: «Fragile. Carefully», «To protect from moisture», «To protect from sunshine», «Restriction of temperature from $+2^{\circ} \mathrm{C}$ to $+4^{\circ} \mathrm{C}$ » and the precautionary inscription «Biological products». Combination of the transport marking and marking characterizing data on the packed production on one party of a transport container isn't allowed. All marking has to be put in the state and Russian languages.

The set is transported all means of transport according to rules of transportation of perishable freights, acting on this type of transport. Transportation of a set is allowed at a temperature up to $20^{\circ} \mathrm{C}$ no more than 15 days.

The set is stored in the dry dark place at a temperature from $2^{\circ} \mathrm{C}$ to $8^{\circ} \mathrm{C}$ separately from animals and livestock production (Figure 10).
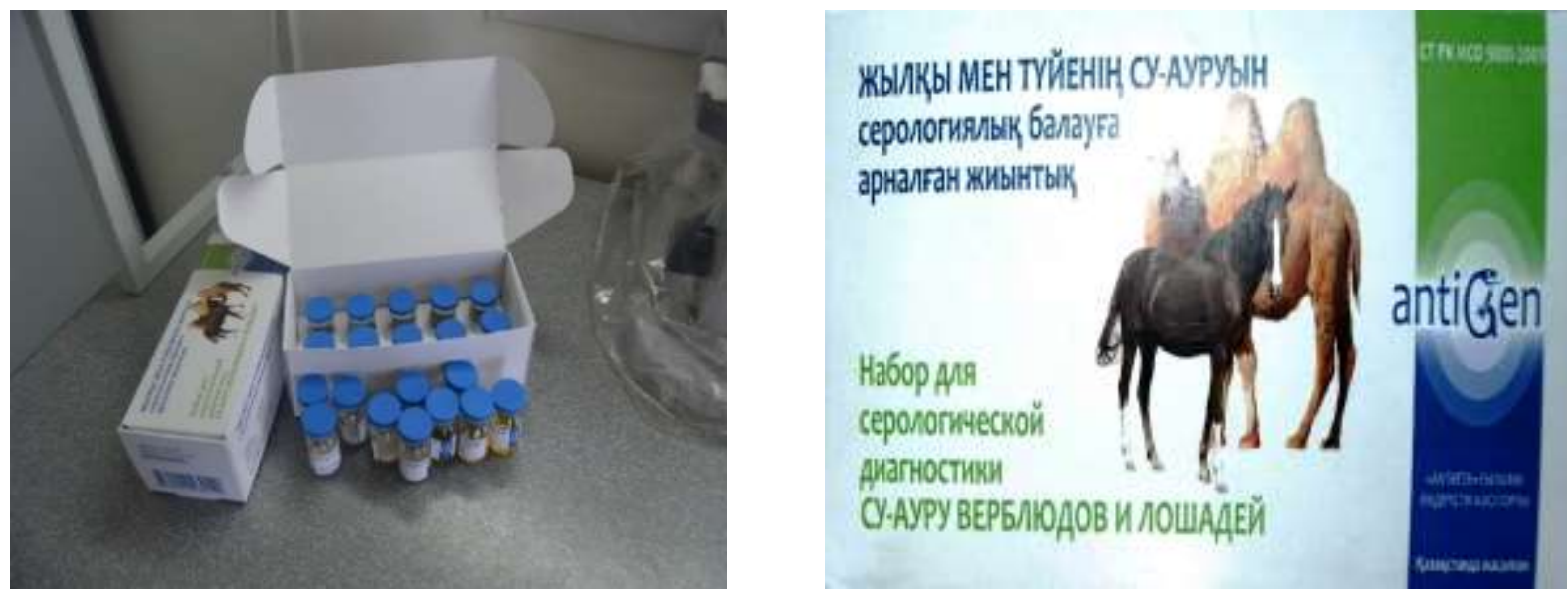

Figure 10:- The set for serologichesky diagnostics of SU aura of camels and horses, is made in NPP «Antigen»

Thus, generalizing results of researches in the course of development and production of the Set for serologichesky diagnostics of a tripanosomoz (sou aura) of camels and horses, positive intermediate results which promoted the solution of a goal have been received:

- Allocation «local» a strain of trypanosomes of Trypanosoma evansi from a sick camel;

- The allocated strain of Trypanosoma evansi is deposited with «scientific research institute of problems of biological safety» at MAUN RK; 
- On a collection strain «The passport of a collection strain of the elementary Trypanosoma evansi» is received;

- The working strain of Trypanosoma evansi is supported at the enterprise on laboratory and closely related animals by repeated passages;

- «The set of biocomponents for serological diagnostics of su auru of camels» is created;

- The ST Standard 10802-1907-TOO-034-2013 on «A set of biocomponents for serological diagnostics of su auru of camels» is approved in the MA RK;

- The set is approved in Republican veterinary laboratory;

- On a set the registration certificate is received for No RK-VP-2-2698-14;

- The set is entered in «The state register of the veterinary preparations and feed additives resolved in the territory of the Republic of Kazakhstan» in 2015;

- Technologies are protected by the Kazakhstan patent No. 27712 «A way of receiving a tripanosome antigene» (2015) [20].

- All technological process of preparation of a set for diagnostics of a tripanosomoz of camels and horses is carried out according to the international guidelines of safety measures of YuNEP in the field of biotechnology and the Code of health of land animals [21, 22].

\section{The used literature:-}

1. Sabanshiyev of M. S. Tripanosomoza of animals (biological properties of activators, epizootologiya, pato-and immunogenesis, diagnostics, fight measures): Diss. bok.biolog sciences. - M, 1993. - 45 pages.

2. Sabanshiyev M. S., Ilgekbayeva G. D., Sayduldin T.S. Efficiency the serologicheskikh of methods of diagnostics at a tripanosomoza of horses//Theses of reports of the V congress of VOPR//Cytology. - M, 1992, No. 4. - T.34. - Page 66.

3. Sabanshiyev M. S., Sayduldin T.S., Ilgekbayeva G. D. Modern methods of diagnostics of a tripanosomoz of horses//Therapy and prevention of parazitoz of farm animals: Sb.nauchny works of KAZNIVI. - Alma-Ata, 1992. - Page 204-208.

4. Epeldimova R. H. Molecular identification of trypanosomes and improvement the tripanosomnykh of diagnostikum for reaction of binding of a complement: yew.... kan. vet. diss - Tyumen, 2002. - Page 51-52.

5. Shabdarbayeva G. S., Akhmetov of G. D. Antidiotypic of an antibody against trypanosomes. Messenger. A series is biological. No. 3 TREASURY of Al-Farabi. Almaty, 2005, S. 62-68.

6. The recommended and alternative tests for diagnosis of list diseases of MEB [An electronic resource] / Chapter 1.3 of the Code of health of land animals//World Health Organization. - Volume 1. General provisions. Nineteenth edition, 2010. - Page 14. - the access Mode: chrome-extension:///http://www.fsvps.ru/fsvpsdocs/ru/.

7. Veterinary requirements of temporary import of the customs territory of the Customs union and (or) movement between the Parties of sports horses for participation in competitions [An electronic resource] / Glava11//Uniform veterinary (veterinary and sanitary) requirements imposed to the goods which are subject to veterinary control (supervision) / Are approved by the Decision of the Commission of the Customs union of June 18, 2010 No. 317. - Access mode: www.ursn72.ru/files/vetnadzor_granitsa/Edinyie_veterinarnyie.doc.

8. Shabdarbaeva G., Nurgazina A., Kozhakov K., Akhmetsadykov N., Akhmetzanova M., Akhmetova G., Husainov D. Extraction of anti-idiotipic antibodies at trypanosomosis of animals // Jornal of International Sceeientific Publication «Agriculture and Food» / Volume 2, ISSN 1314-8591 (Online), Published at: http://www.scientific-publications.net.

9. Georgiu X. RDSK, RNGA and IFA at diagnostics of tripanosomoz of horses//Materials V of scientific and practical conference on diseases of horses, - 2004. - Page 19-22.

10. Shabdarbayeva G. S. Immunobiological aspects of designing of diagnostic on the basis of an antiidiotipiya for identification of blood-parazitoz of animals//Diss. bok.biolog sciences, Almaty, 2007. Page 144-148.

11. Shabdarbayeva G.S., Akhetsadykov N.N., Balgimbayeva A.I., Khusainov D.M., Amirgaliyeva S.S., Turganbayeva G. E., Akhmetova G. D., Kozhakov K.K. «Way of receiving a tripanosomoz anti-gene» [eel.res] / Innovative patent No. 27712//Industrial property. Official bulletin of Committee on intellectual property rights of MYuRK. - bulletin No. 12.-2013. - Access mode: https://gosreestr.kazpatent.kz/ru/.

12. Hachoyan V. I., Nalbandian E.S. Flotation and separation of trypanosomes from uniform elements of blood//Biol. journal. Armenia. - 1967. - T.20, No. 2. - Page 99-101.

13. Shabdarbayeva G. S., Akhmetsadykov N. N., Ivanov N. P., Khusainov D.M., etc. A way of receiving antipyroplasma serum//the RK Innovative patent for the invention No. 22021 from 10/26/2009.

14. Fey M., Pfietter H.,Messerli I., Sturzenegger N., Crolimud F. Methods of Isolation, Purification and Quantitation of Bovine Immunoglobulins.//Ibl.Vet.Med.- 1976.-23.- P. 269-300. 
15. Frimel G. Immunological methods. - 1987. Page 56-57.

16. Frimel G. Immunological methods. - 1987. Page 87-88.

17. Shabdarbayeva G. S., Akhmetsadykov N. N., Ivanov N. P., Khusainov D.M., Kozhayev A.N., etc. A way of receiving a preparation for diagnostics of a tripanosomoz//the RK Innovative patent for the invention No. 22023 from 10/26/2009.

18. Shabdarbayeva G. S., Akhmetsadykov N. N., Balgimbayeva A.I., Khusainov D.M., Amirgaliyeva S.S., Turganbayeva G. E., Akhmetova G. D., Kozhakov K.K. A way of receiving a tripanosomozny anti-gene//RK Innovative patent No. 27712 from 11/22/2013.

19. Heidelberger M. The molecular cjmposition of specific immune precipitation from rabbit sera.//J.Amer.Chem.Sac.-1938.-60.-P.242-244.

20. The RK patent No. 27712 - «A way of receiving a tripanosomozny anti-gene», 2015. Is published in the official bulletin RK «Industrial Property» No. 12 from 12/15/2015 (Shabdarbayeva G. S., Akhmetsadykov N. N., Balgimbayeva A.I., Khusainov D.M., etc.).

21. The international guidelines of safety measures of YuNEP in the field of biotechnology//YuNEP. 1995. 39 pages.

22. Code of health of land animals [An electronic resource] / Chapter 5.2. - A passport sample for movement of sports horses. - MEB, 2012. - Page 258. - Access mode: / http://web.oie.int/RR-Europe/eng/Code/. 